\title{
Investigation of CCL18 and A1AT as potential urinary biomarkers for bladder cancer detection
}

\author{
Makito Miyake', Shanti Ross ${ }^{1}$, Adrienne Lawton ${ }^{2}$, Myron Chang ${ }^{3}$, Yunfeng Dai ${ }^{3}$, Lourdes Mengual ${ }^{4}$, \\ Antonio Alcaraz ${ }^{4}$, Evan Gomes Giacoia ${ }^{1}$, Steve Goodison ${ }^{1,5}$ and Charles J Rosser ${ }^{1,5,6^{*}}$
}

\begin{abstract}
Background: In this study, we further investigated the association of two biomarkers, CCL18 and A1AT, with bladder cancer (BCa) and evaluated the influence of potentially confounding factors in an experimental model.

Methods: In a cohort of 308 subjects (102 with BCa), urinary concentrations of CCL18 and A1AT were assessed by enzyme-linked immunosorbent assay (ELISA). In an experimental model, benign or cancerous cells, in addition to blood, were added to urines from healthy controls and analyzed by ELISA. Lastly, immunohistochemical staining for CCL18 and A1AT in human bladder tumors was performed.

Results: Median urinary protein concentrations of CCL18 $(52.84 \mathrm{pg} / \mathrm{ml}$ vs. $11.13 \mathrm{pg} / \mathrm{ml}, p<0.0001)$ and A1AT $(606.4 \mathrm{ng} / \mathrm{ml}$ vs. $120.0 \mathrm{ng} / \mathrm{ml}, p<0.0001)$ were significantly elevated in BCa subjects compared to controls. Furthermore, the addition of whole blood to pooled normal urine resulted in a significant increase in both CCL18 and A1AT. IHC staining of bladder tumors revealed CCL18 immunoreactivity in inflammatory cells only, and there was no significant increase in these immunoreactive cells within benign and cancerous tissue and no association with BCa grade nor stage was noted. A1AT immunoreactivity was observed in the cytoplasm of epithelia cells and intensity of immunostaining increased with tumor grade, but not tumor stage.
\end{abstract}

Conclusions: Further development of A1AT as a diagnostic biomarker for BCa is warranted.

Keywords: Biomarkers, Bladder cancer, Specificity, Urine

\section{Background}

Non-invasive urine tests for the early detection or postsurgical surveillance of bladder cancer (BCa) are highly desirable for both the patient and the healthcare system. Currently, voided urinary cytology (VUC) is the most widely used non-invasive urine test, with reported specificities ranging from $85-100 \%$ and sensitivities ranging from $13-75 \%[1,2]$. Two single-protein biomarker urinebased assays, bladder tumor antigen (BTA) test and nuclear matrix protein-22 (NMP-22) test, have been developed and FDA approved for use in this context. However, these assays have significant limitations. The BTA tests (BTA stat ${ }^{\mathrm{ma}}$ and BTA TRAK ${ }^{\mathrm{mt}}$ (Polymedco Inc. Cortlandt Manor, NY, USA) have diagnostic sensitivities ranging from $29-83 \%$ and specificities ranging from $56-86 \%$

\footnotetext{
* Correspondence: deacdoc@aol.com

'Cancer Research Institute, Orlando Health, Orlando, FL 32827, USA

${ }^{5}$ Nonagen Bioscience Corporation, Orlando, FL 32827, USA

Full list of author information is available at the end of the article
}

$[3,4]$. In addition, we and others have demonstrated in an experimental model that hematuria adversely affects the accuracy of the BTA assay $[5,6]$. The NMP-22 tests (NMP22 ${ }^{\circ}$ Bladder Cancer ELISA Test Kit and the NMP22 ${ }^{\circ}$ BladderChek $^{\bullet}$ point-of-care test, Alere Scarborough, Inc. Waltham, MA) have diagnostic sensitivities ranging from $47-100 \%$ and specificities ranging from 55-98\% [7,8]. Atsu et al. and others have recently demonstrated in an experimental model that NMP-22 assays measure the cellularity or amount of cell turnover that may be introduced into the urine by a variety of conditions, including hematuria, infection and instrumentation $[9,10]$. Thus, the search for more accurate urine-based biomarkers continues.

Through genomic and proteomic profiling of urine components, we have previously identified a panel of biomarkers that can outperform current urine-based biomarkers for the non-invasive detection of $\mathrm{BCa}$ [11-14]. In a case-controlled validation study, the urinary concentrations of our panel of 14 biomarkers (IL-8, 
MMP-9, MMP-10, SDC1, CCL18, PAI-1, CD44, VEGF, ANG, CA9, A1AT, SPP1, PTX3, and APOE) were measured by enzyme-linked immunosorbent assay (ELISA) in voided urines from 127 patients (64 tumor bearing subjects) [15-18]. Of these 14 biomarkers, two biomarkers (CCL18 and A1AT) had high correlation coefficients (Spearman correlation coefficient >0.76) with urinary blood content and therefore, rather than measuring a valid tumor antigen the biomarker may be merely a surrogate for hematuria. Subsequently, these two biomarkers have been excluded from ongoing multiplex studies [19] until we can clarify the source of these protein biomarkers. Herein, we report the urinary concentrations of CCL18 and A1AT in an independent larger case-control study, and illustrate in an experimental model the influence of cellular proteins and whole blood on the performance of these potential urine-based biomarkers.

\section{Methods}

\section{Ethics statement}

Under Institutional Review Board approval by the committees at MD Anderson Cancer Center Orlando and Hospital Clinic of Barcelona, written informed consent was obtained prior to collection and storage of biological specimens (voided urine samples and blood) in genitourinary biorepositories. Furthermore under Institutional Review Board approval by the committee at MD Anderson Cancer Center Orlando with a waiver of written informed consent, archived bladder tissues from the Department of Pathology at Orlando Health was identified for immunohistochemical analysis. The above review boards monitored study recruitment and study compliance.

\section{Patients and data collection}

For the urinary ELISA validation study, 308 nonconsecutive subjects (102 with BCa) from MD Anderson Cancer Center Orlando and Hospital Clínic of Barcelona were available for analysis. The control cohort consisted of 206 individuals (47 with voiding symptoms, 44 with urolithiasis, 9 with gross hematuria, 14 with urinary tract infection and 92 without any diagnosed condition). Patients with a history of renal dysfunction were excluded. The cohort of 308 subjects served as our phase II (validation study) according to the International Consensus Panel on Bladder Tumor Markers and findings were reported according to the STARD criteria [20]. For the experimental model, three healthy volunteers ( 2 males, 1 female, mean age 36 years) provided urine and blood samples. For the immunohistochemical study, formalin-fixed paraffin embedded blocks containing 165 bladder tumor tissue specimens and 8 benign tissue specimens were retrieved from the Orlando Health Department of Pathology.

\section{Specimen processing}

Fifty milliliters of voided urine from each subject was assigned a unique identifying number before delivery to the laboratory for processing. Each urine sample was centrifuged at $1000 \times g 4^{\circ} \mathrm{C}$ for $10 \mathrm{~min}$. The supernatant was decanted and aliquoted, and the urinary pellet was snap frozen. Both the supernatant and pellet were stored at $-80^{\circ} \mathrm{C}$ prior to analysis. Urine supernatant protein concentration was determined using Pierce 660-nm Protein Assay Kit (Thermo Fisher Scientific Inc., Waltham, MA, USA). Patients with significant proteinuria were excluded.

\section{Enzyme-linked immunosorbent assays for urinary CCL18 and A1AT}

The levels of human CCL18 (Cat \# ab100620, Abcam, Cambridge, MA) and human A1AT (Cat\# ab108799, Abcam) in urine samples were monitored using ELISA. The assays were conducted according to the manufacturer's instructions. Laboratory personnel were blinded to final diagnosis. Calibration curves were prepared using purified standards for each protein assessed. Curve fitting was accomplished by either linear or four-parameter logistic regression following manufacturer's instructions. Urinary creatinine levels were monitored with a commercial ELISA assay (Cat\# KGE005 R\&D Systems Inc., Minneapolis, MN, USA) as previously described [21].

\section{Cell lines and culture}

Human bladder cancer cell lines T24 (ATCC, Manassas, VA) and UM-UC-14 (a generous gift from Dr. H. Bart Grossman, The University of Texas M.D. Anderson Cancer Center, Houston, TX) [22] were available for analysis. The benign human bladder cell line, UROtsa, was a generous gift from Dr. Donald Sens at the University of North Dakota School Of Medicine (Grand Forks, ND) [23]. T24 and UM-UC-14 cell lines were maintained in RPMI 1640 media. UROtsa cells were maintained in McCoy's 5A medium (Life Technologies, Inc., Gaithersburg, MD). All media were supplemented with $10 \%$ fetal bovine serum, 100 units $/ \mathrm{ml}$ of penicillin and $100 \mu \mathrm{g} / \mathrm{ml}$ of streptomycin. All cells were incubated at $37^{\circ} \mathrm{C}$ in a humidified atmosphere of $5 \% \mathrm{CO}_{2}$.

\section{Experimental model}

The experimental model was essentially as previously published [6,10]. Figure 1 illustrates the experimental model components and dilutions. Briefly, 10 milliliters of whole blood in heparinized tube and $200 \mathrm{ml}$ of freshly voided urine samples in sterile containers were obtained from three healthy controls. The urine samples from the three healthy subjects were pooled, mixed and distributed into $10 \mathrm{ml}$ aliquots in $15 \mathrm{ml}$ centrifuge tubes. The human bladder cell lines were washed, trypsinized and counted. For UROtsa, $1 \times 10^{4}$ cells (low concentration), 

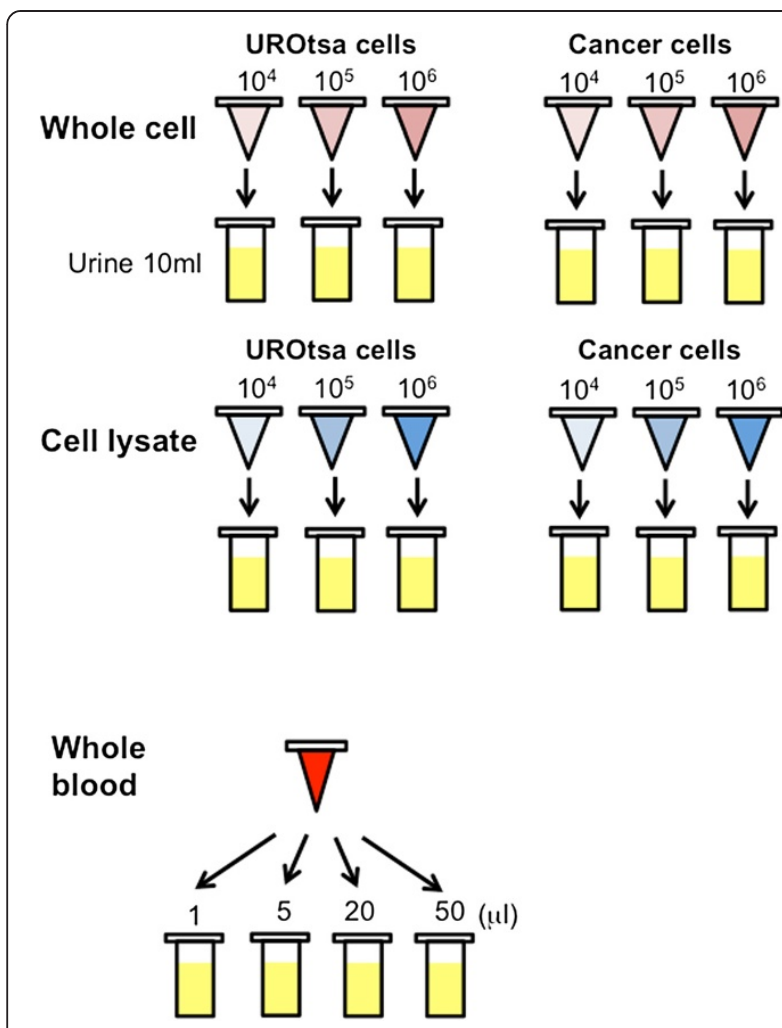

Figure 1 Schematic of the experimental model. Low concentration $\left(1 \times 10^{4}\right)$, medium concentration $\left(1 \times 10^{5}\right)$ and high concentrations $\left(1 \times 10^{6}\right)$ of intact UROtsa benign human bladder cells, or a mixture of human bladder cancer lines, T24 and UM-UC-14 were added to $10 \mathrm{ml}$ of pooled urine from three healthy controls. Low protein concentration of cellular lysate $(4 \mu \mathrm{g})$, medium concentration $(40 \mu \mathrm{g})$ and high concentrations $(400 \mu \mathrm{g})$ of UROtsa benign human bladder cells, or from a mixture of human bladder cancer lines, T24 and UM-UC-14 were added to $10 \mathrm{ml}$ of pooled urine from three healthy controls. Whole blood $(1,5,20$ and $50 \mu l)$ was also added to $10 \mathrm{ml}$ of pooled urine from healthy controls.

$1 \times 10^{5}$ cells (medium concentration) and $1 \times 10^{6}$ cells (high concentration) cells were each added to $10 \mathrm{ml}$ pooled urine samples in triplicate. Equal numbers of T24 and UM-UC-14 were pooled, and $1 \times 10^{4}$ pooled cells (low concentration), $1 \times 10^{5}$ pooled cells (medium concentration) and $1 \times 10^{6}$ pooled cells (high concentration) cells were added to $10 \mathrm{ml}$ of pooled urine samples in triplicate. For cell lysate analyses, $1 \times 10^{6}$ cells from each cell line were lysed with RIPA buffer (Pierce, Rockford, IL) and total protein concentration measured. The total protein extracted from $1 \times 10^{6}$ cells of UROtsa, T24 and UM-UC-14 were $431 \mu \mathrm{g}, 471 \mu \mathrm{g}, 280 \mu \mathrm{g}$ and $420 \mu \mathrm{g}$, respectively, with a mean total protein extract of $400 \mu \mathrm{g}$. In the spiking experiments, $4 \mu \mathrm{g}, 40 \mu \mathrm{g}$ and $400 \mu \mathrm{g}$ of cellular proteins from either UROtsa or the pooled $\mathrm{BCa}$ cell lines were used, corresponding to $\sim 1 \times 10^{4}$ cells (low concentration), $\sim 1 \times 10^{5}$ cells (medium concentration) and $\sim 1 \times 10^{6}$ cells (high concentration).
UROtsa lysates and pooled cancer cell lysates were added to pooled urine samples in triplicate. To monitor the influence of hematuria, pooled whole blood from three healthy subjects was added in triplicate to $10 \mathrm{ml}$ of pooled urine samples in the following amounts; $1 \mu \mathrm{l}, 1 /$ 10000 final dilution; $5 \mu \mathrm{l}, 1 / 2000$ final dilution; $20 \mu \mathrm{l}, 1 /$ 500 final dilution; $50 \mu \mathrm{l}, 1 / 200$ final dilution and zero control. The number of red blood cells (RBC) in each urine sample was determined by microscopic examination before and after adding whole blood. Standard urinalysis was performed with MULTISTIX PRO Reagent Strips (Bayer HealthCare, Elkhart, IN).

\section{Immunohistochemistry}

A total of 173 paraffin blocks were verified histologically by H\&E staining. For immunochemical staining, blocks were cut in $5 \mu \mathrm{m}$ sections and placed on a Superfrost Plus Miscroslide. Sections were deparaffinized, followed by antigen retrieval using citric acid buffer $\left(\mathrm{pH} 6.0,95^{\circ} \mathrm{C}\right.$ for 20 $\mathrm{min})$. The slides were treated with $1 \%$ hydrogen peroxide in methanol to block endogenous peroxidase activity. After 20 min blocking in $1 \%$ bovine serum albumin (BSA), the slides were incubated overnight at $4{ }^{\circ} \mathrm{C}$ with anti-human CCL18 antibody (MAB394; mouse monoclonal, dilution 1/500 in 1\% BSA) from R\&D Systems Inc., or anti-human A1AT antibody (NBP1-90309; rabbit polyclonal, dilution 1/2500 in 1\% BSA) from Novus Biologicals Inc. (Littleton, CO). Next, the slides were incubated with $2 \mu \mathrm{g} / \mathrm{mL}$ of biotinylated anti-mouse or anti-rabbit IgG secondary antibody (Vector Laboratories, Burlingame, CA) for $30 \mathrm{~min}$ at room temperature. Subsequently, the sections were stained using Standard Ultra-Sensitive ABC Peroxidase Staining kit (Pierce/Thermo Fisher Scientific, San Jose, CA) and 3, 3'diaminobenzidine (DAB; Vector Laboratories), counterstained by hematoxylin, dehydrated, and mounted with a cover slide. Human liver, known to stain strongly for CCL18 and A1AT, was used as a positive control, and negative controls were performed by omitting the primary antibodies. Using light microscopy, two investigators (MM and $\mathrm{AL}$ ) interpreted immunostaining results blinded to specimen and patient data. A third investigator (CJR) reviewed discrepancies and rendered a final score. The location of immunoreactivity (e.g., nuclear, cytoplasm, cell membrane, and stroma) was noted. CCL18 immunostaining was positive only in inflammatory cells in the stroma. Three randomly chosen high power fields $\left(1 \mathrm{HPF}=0.237 \mathrm{~mm}^{2}\right)$ were analyzed for CCL18-positive cells in the stromal area and averaged in each case. A1AT immunostaining was positive only in the cytoplasm of epithelial cells. Immunostaining intensity was reported as weak, moderate or strong.

\section{Data analysis}

The Wilcoxon rank sum test was used on ELISA data to determine the association between urinary CCL18, 
A1AT and BCa status. Nonparametric receiver operating characteristic (ROC) curves were plotted and the ability of the biomarker to predict the presence of $\mathrm{BCa}$ was estimated by calculating the area under the ROC curves (AUROC). The sensitivity and specificity of the biomarker at the optimal cutoff value was defined by calculating the Youden index [24]. Comparison of immunohistochemical distribution data was performed using Chi square test. Spearman rank correlation coefficients were used to examine the correlation between urinary CCL18 and A1AT concentrations and urinary hemoglobin concentration. The association between CCL18 and A1AT levels and BCa was tested using the Mann Whitney test. Statistical significance in this study was set at $p<0.05$ and all reported $p$ values were 2 -sided. All analyses were performed using PRISM software version 5.00 (San Diego, CA).

\section{Results}

CCL18 and A1AT in voided urine samples

Table 1 depicts demographics and clinical characteristics of the study cohorts. Ninety percent of the BCa subjects sampled were Caucasian (median age 69 years) with $60 \%$ noted to have non-muscle invasive bladder cancer (NMIBC) and 37\% with low-grade disease. In the cancer cohort, urinary cytology achieved a diagnostic sensitivity of $39 \%$. Median urinary protein concentrations of CCL18 (52.84 pg/ml vs. $11.13 \mathrm{pg} / \mathrm{ml}, p<0.0001)$ and A1AT (606.4 ng/ml vs. $120 \mathrm{ng} / \mathrm{ml}, p<0.0001)$ were significantly elevated in $\mathrm{BCa}$ subjects compared to controls. Furthermore, median urinary CCL18 was significantly elevated in muscle invasive bladder cancer (MIBC) compared to NMIBC (90.65 pg/ml vs. $44.72 \mathrm{pg} / \mathrm{ml}$, $p=0.044$ ), and approached significance (Figure 2a) in high-grade compared to low-grade disease $(79.57 \mathrm{pg} / \mathrm{ml}$ vs. $38.10 \mathrm{pg} / \mathrm{ml}, p=0.073)$. Similarly, median urinary

Table 1 Demographic and clinicopathologic characteristics of 308 subjects comprising ELISA study cohort and 173 subjects comprising IHC study cohort

\begin{tabular}{|c|c|c|c|c|}
\hline & \multicolumn{2}{|c|}{ ELISA Cohort } & \multicolumn{2}{|c|}{ IHC Cohort } \\
\hline & $\mathrm{BCa}(\%) \mathrm{n}=102$ & Controls (\%) $n=206$ & BCa (\%) $n=165$ & Controls (\%) $n=8$ \\
\hline Median Age (range, y) & $69(20-93)$ & $56(18-89)$ & $67(47-91)$ & $59(42-83)$ \\
\hline Male : Female ratio & $84: 18$ & $152: 54$ & $132: 33$ & $7: 1$ \\
\hline \multicolumn{5}{|l|}{ Race } \\
\hline White & 91 (90\%) & $135(66 \%)$ & $137(83 \%)$ & 7 (88\%) \\
\hline African American & $5(5.9 \%)$ & $20(10 \%)$ & $8(5 \%)$ & $0(0 \%)$ \\
\hline Other & $6(6.1 \%)$ & $51(24 \%)$ & $20(12 \%)$ & $1(12 \%)$ \\
\hline Positive FISH & $40 / 74$ (54\%) & $2 / 22(9 \%)$ & N/A & N/A \\
\hline Suspicious/positive cytology & 37 / 94 (39\%) & $2 / 22(9 \%)$ & N/A & N/A \\
\hline Median follow-up (months) & 14 & 4 & 11 & 3 \\
\hline \multicolumn{5}{|l|}{ Clinical stage } \\
\hline Tis & $6(6 \%)$ & & $15(9 \%)$ & \\
\hline $\mathrm{Ta}$ & $41(40 \%)$ & & $15(9 \%)$ & \\
\hline T1 & $14(14 \%)$ & & 15 (9\%) & \\
\hline$\geq \mathrm{T} 2$ & $41(40 \%)$ & & $120(73 \%)$ & \\
\hline \multicolumn{5}{|l|}{ Tumor grade } \\
\hline Low & $38(37 \%)$ & & $36(22 \%)$ & \\
\hline High & $64(63 \%)$ & & $129(78 \%)$ & \\
\hline Median tumor size $(\mathrm{cm})$ & 3.0 & & 3.5 & \\
\hline \multirow[t]{2}{*}{ Median urinary CCL18 pg/ml (range) } & 52.84 & 11.13 & & \\
\hline & $(2-6949)$ & $(0-662)$ & & \\
\hline \multirow[t]{2}{*}{ Median urinary A1AT ng/ml (range) } & 606.4 & 120.0 & & \\
\hline & $(26-8830)$ & $(1-1997)$ & & \\
\hline \multirow[t]{2}{*}{ Median urinary protein $\mu \mathrm{g} / \mathrm{ml}$ (range) } & 24.2 & 38.9 & & \\
\hline & $(24-789)$ & $(24-561)$ & & \\
\hline
\end{tabular}



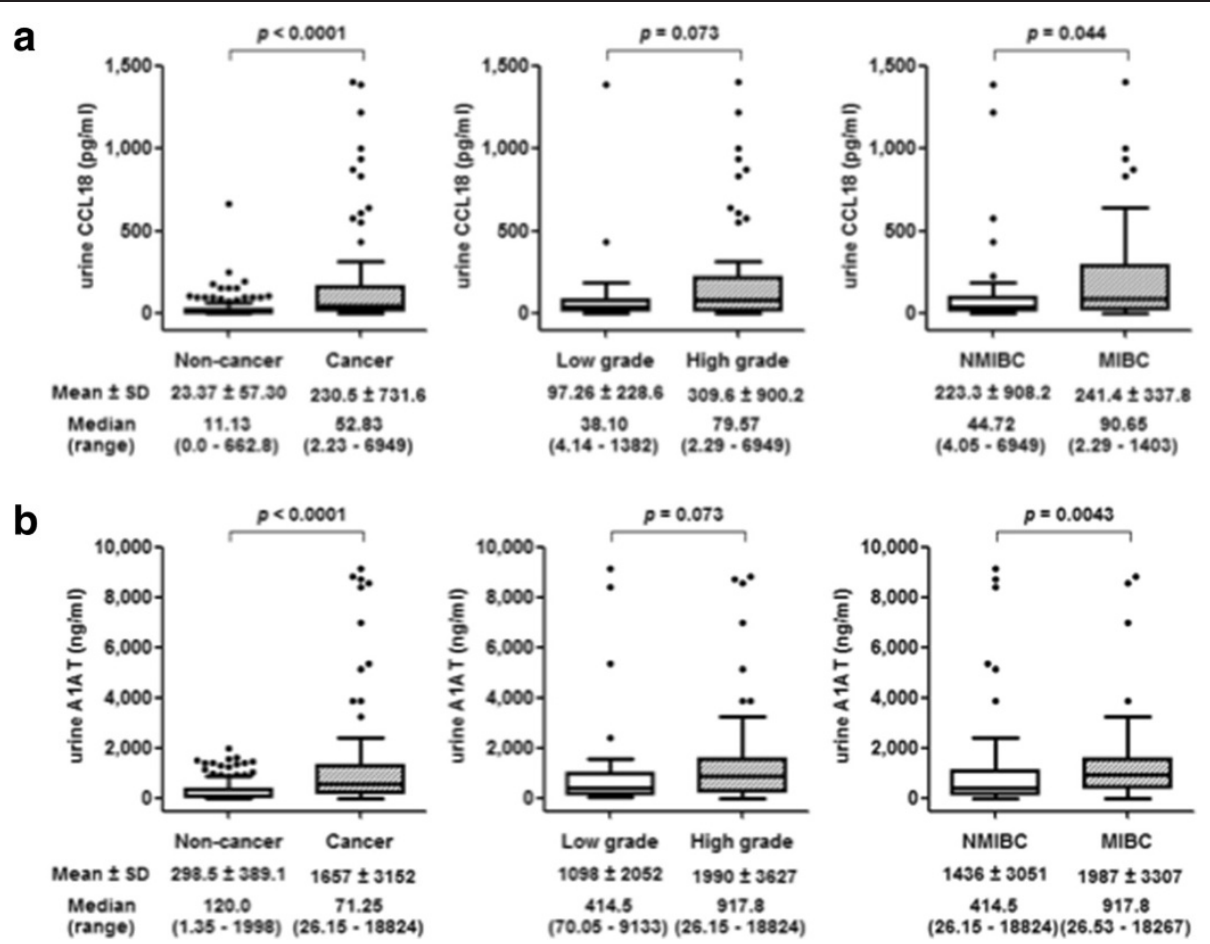

Figure 2 Urinary biomarker levels. a) Comparison of urine concentrations of CCL-18 between the cancer and non-cancer groups (left panel), low-grade and high-grade (middle panel) and non-muscle invasive bladder cancer (NMIBC) and muscle-invasive bladder cancer (MIBC). b) Comparison of urine concentrations of A1AT between the same groups. Median levels are depicted by horizontal lines within boxes, standard deviations are depicted by bars. Significance $(p<0.05)$ was assessed by the Wilcoxon rank sum test.

A1AT was significantly elevated in MIBC compared to NMIBC $(978.1 \mathrm{ng} / \mathrm{ml} v s .414 .5 \mathrm{ng} / \mathrm{ml}, p=0.0042)$ and approached significance (Figure $2 \mathrm{~b}$ ) in high-grade compared to low-grade $(917.8 \mathrm{ng} / \mathrm{ml}$ vs. $414.5 \mathrm{ng} / \mathrm{ml}$, $p=0.073)$. The ability of the tested biomarkers to predict the presence of $\mathrm{BCa}$ was analyzed using nonparametric ROC analyses, according to National Cancer Institute guidelines [25]. Based on the AUROC, we determined Youden index cutoff values to maximize the sum of sensitivity and specificity. Urinary CCL18 had an area under the curve of 0.768 (95\% CI: 0.713-0.824) (Figure 3), achieved a sensitivity of $70.4 \%$, specificity of $67.7 \%$, positive predictive value of $53.1 \%$ and a negative predictive value of $81.5 \%$. Urinary A1AT had an area under the curve of 0.775 (95\% CI: 0.721-0.829) (Figure 3), achieved a sensitivity of $70.6 \%$, specificity of $71.8 \%$, positive predictive value of $55.4 \%$ and negative predictive value of $83.2 \%$.

\section{Experimental model}

Urine and blood samples were obtained from three healthy volunteer controls for analysis in the experimental model. There was no evidence of gross hematuria, urinary tract infection or any biochemical abnormalities in any volunteer urine samples. Both urinary dipstick and urinary microscopy were negative for hematuria, however, urinary hemoglobin measured by ELISA assay revealed trace amounts in all samples $(3.63 \pm 0.59 \mathrm{ng} /$ $\mathrm{ml})$. In these healthy controls, the mean urinary CCL18 level was $5.96 \pm 7.73 \mathrm{pg} / \mathrm{ml}$, and the mean urinary A1AT level was $1170 \pm 71.94 \mathrm{ng} / \mathrm{ml}$ (Table 2).

Urine samples were pooled, and whole cells or cell lysates of the cancer cell line pool and UROtsa cells were added to the urine sample (as depicted in Figure 1) and re-analyzed for CCL18 and A1AT using ELISA. The addition of a high concentration $(400 \mu \mathrm{g})$ of protein lysate from UROtsa cells, or medium to high concentration (40 $\mu \mathrm{g}$ to $400 \mu \mathrm{g})$ of protein lysate from pooled cancerous cells resulted in a significant increase in test sample CCL18 (Additional file 1). Furthermore, the addition of whole blood $(50 \mu \mathrm{L})$ resulted in a significant increase in CCL18 $(p<0.05)$ (Figure 4). As for A1AT, the addition of high concentration of whole blood $(50 \mu \mathrm{L})$ resulted in a significant increase in test sample A1AT levels $(p<0.05)$ (Figure 4).

With the addition of only $1 \mu \mathrm{l}$ of whole blood to $10 \mathrm{~mL}$ of test urines $(1 / 10,000$ dilution), the mean urinary hemoglobin level was $174.28 \pm 15.69 \mathrm{ng} / \mathrm{ml}$, and microscopy revealed a median $1 \mathrm{RBC} / \mathrm{hpf}$. This level would be termed 'Negative' or 'Trace' in clinical tests such as the Multistix Pro dipstick test (negative blood is $<100 \mathrm{ng} / \mathrm{ml}$ ). At this level, CCL18 and A1AT concentrations were 


\section{CCL18}

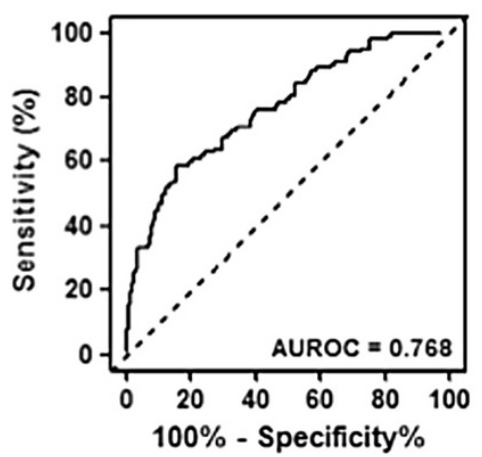

A1AT

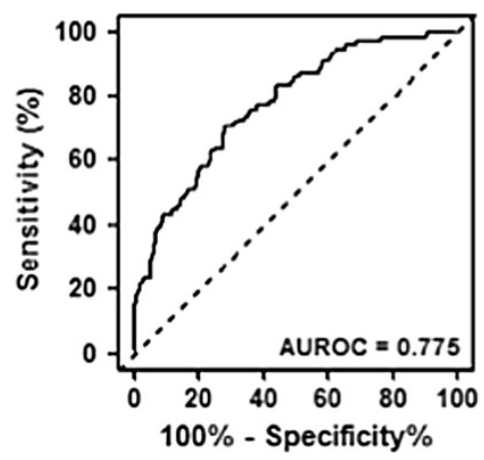

Figure 3 Diagnostic performance of urinary CCL18 and A1AT. Receiver operator characteristic (ROC) curves were calculated from the analysis of urine samples obtained from a cohort of 308 subjects (102 with confirmed bladder cancer) for CCL18 and A1AT. AUROC, area under the ROC curve.

unaffected at $7.06 \pm 7.78 \mathrm{ng} / \mathrm{ml}$ and $1227.31 \pm 1.22 \mathrm{ng} / \mathrm{ml}$, respectively. With the addition of $50 \mu \mathrm{l}$ of whole blood to $10 \mathrm{~mL}$ of urine, all urines had visibly gross hematuria, the mean urinary hemoglobin level was 7,898.05 $\pm 184.67 \mathrm{ng} /$ $\mathrm{ml}$ and median of $17 \mathrm{RBC} / \mathrm{hpf}$ was noted. At this level, CCL18 concentration was raised to $31.90 \pm 43.19 \mathrm{ng} / \mathrm{ml}$ ( 4.5 fold increase), but the A1AT concentration was similar to controls at $1,273.16 \pm 5.53 \mathrm{ng} / \mathrm{ml}$ (Table 2). As the concentration of whole blood added to the urine samples increased, the mean urinary hemoglobin level, the extent of hematuria assessed by microscopy, and the mean urinary concentrations of CCL18 and A1AT increased accordingly (Table 2). There were high correlation coefficients between hemoglobin and CCL18 (Spearman correlation coefficient $=0.90$ ) and hemoglobin and A1AT (Spearman correlation coefficient $=1.00)$.

\section{Immunohistochemical analysis of bladder tumors}

The study cohort consisted of 8 subjects without cancer and 165 non-consecutive subjects with $\mathrm{BCa}$ (37 subjects with low-grade $\mathrm{BCa}$ and 128 subjects with high-grade $\mathrm{BCa}, 45$ subjects with NMIBC and $120 \mathrm{MIBC})$. Immunohistochemical staining patterns for CCL18 and A1AT were assessed in both malignant and normal bladder tissue. No epithelial staining was evident for CCL18, however, inflammatory cells in the stromal were positive.
The number of CCL18-positive inflammatory cells per high power field was not increased in bladder tumors compared to controls $(1.0 \pm 1.2 v s .4 .5 \pm 6.9, p=0.57)$. In addition, an increase in CCL18-positive inflammatory cells was not associated with higher grade or higher stage disease (Figure 5a). Immunostaining for A1AT revealed a predominantly epithelial and cytoplasmic localization. Intensity of staining ranged from weak and focal to strong and diffuse. No difference in staining intensity was seen between benign and cancer $(p=0.99)$. Staining intensity increased with an increase in tumor grade $(p=0.05)$, however, staining pattern was not significantly associated with tumor stage $(p=0.79)$ (Figure $5 \mathrm{~b})$.

\section{Discussion and conclusions}

We have previously identified CCL18 and A1AT as potential biomarkers for the detection of $\mathrm{BCa}$ in voided urine samples $[15,18]$. CCL18 is a member of the serumbased cytokine family of secreted proteins involved in immunoregulatory and inflammatory processes. CCL18 is thought to promote the invasiveness of cancer cells by triggering integrin clustering and enhancing their adherence to the extracellular matrix, and a receptor (PITPNM3) for this cytokine has been recently identified [26]. CCL18 has been identified in gynecological tumors

Table 2 Results of CCL18 and A1AT in experimental hematuria model

\begin{tabular}{|c|c|c|c|c|c|}
\hline \multirow{2}{*}{$\begin{array}{l}\text { Dilution (volume } \\
\text { of whole blood) }\end{array}$} & \multirow{2}{*}{$\begin{array}{c}\text { Red blood } \\
\text { cells ( /hpf* })\end{array}$} & \multicolumn{3}{|c|}{ Concentration (mean \pm SD) } & \multirow{2}{*}{$\begin{array}{l}\text { Urinary protein } \\
\text { (dipstick test) }\end{array}$} \\
\hline & & Hemoglobin (ng/ml) & CCL18 (pg/ml) & A1AT (ng/ml) & \\
\hline 0 & $0 \pm 0$ & $3.63 \pm 0.59$ & $5.96 \pm 7.73$ & $1170.70 \pm 71.94$ & negative \\
\hline $1 / 10,000(1 \mu l)$ & $0.6 \pm 1.0$ & $174.28 \pm 15.69$ & $7.06 \pm 7.78$ & $1227.31 \pm 1.22$ & negative \\
\hline $1 / 2,000(5 \mu l)$ & $2.4 \pm 1.2$ & $2289.34 \pm 479.07$ & $6.80 \pm 9.61$ & $1252.49 \pm 2.92$ & $30 \mathrm{mg} / \mathrm{dL}$ \\
\hline $1 / 500(20 \mu l)$ & $10.0 \pm 4.4$ & $3633.39 \pm 2006.87$ & $16.62 \pm 22.17$ & $1258.43 \pm 13.48$ & $100 \mathrm{mg} / \mathrm{dL}$ \\
\hline $1 / 200(50 \mu l)$ & $17.3 \pm 3.0$ & $7898.05 \pm 184.67$ & $31.90 \pm 43.19$ & $1273.16 \pm 5.53$ & 300 mg/dL \\
\hline
\end{tabular}

${ }^{*} h p f$ high power field. 


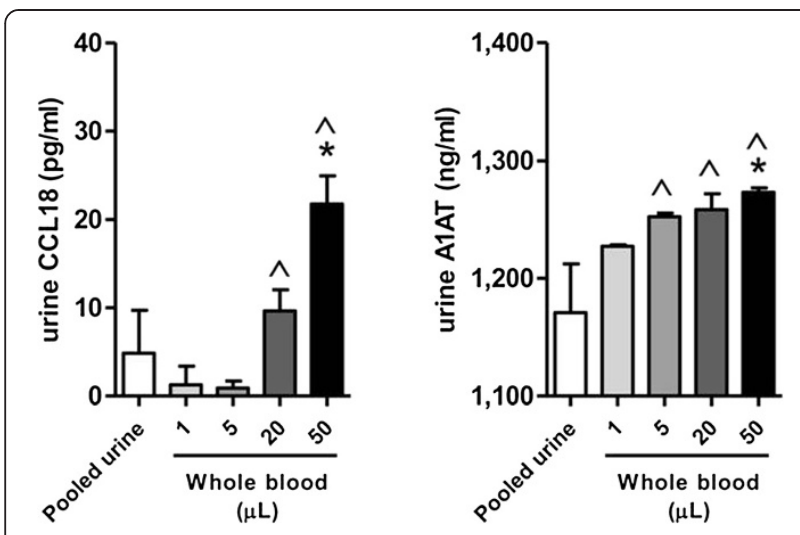

Figure 4 Analysis of CCL18 and A1AT biomarker performance in an experimental model. Using the experimental model depicted in Figure 1, urinary levels of CCL18 and A1AT were analyzed by ELISA. The addition of whole blood resulted in an increase in CCL18 as well as an increase in A1AT. Error bars indicate standard deviations. ${ }^{*}$, significance $(p<0.05)$ compared to pooled urines from healthy subjects. $\wedge$, significance $(p<0.05)$ compared to corresponding lower concentration.

but not urologic tumors [27,28]. A1AT, also known as SERPINA1, is a member of a family of serine proteases inhibitors. Specifically A1AT irreversibly inhibits trypsin, chymotrypsin and plasminogen activator. Serpins are known to have diverse but critical roles in the cell, including regulation of homeostasis, cellular survival and blood clotting [29]. Within the oncology literature, reports describe genetic aberrations in cancers, elevated levels in the sera of cancer patients, and survival disadvantage in tumors expressing A1AT [30,31].

In our early studies, we noted that these biomarkers had a relatively high correlation (Spearman correlation coefficient > 0.76) with urinary hemoglobin. Given the confounding effects of hematuria that we and others have described for the urine-based $\mathrm{BCa}$ detection assays BTA and NMP-22 $[6,10]$, we set out to more methodically analyze the association of CCL18 and A1AT with $\mathrm{BCa}$ by analyzing cohorts of urine and tissue samples. In this study, ELISA analysis of urine samples from a cohort of 308 subjects confirmed our previous findings [19] that both CCL18 and A1AT are significantly elevated in the urines of subjects with $\mathrm{BCa}$.

To investigate the potential influence of hematuria and other factors on the performance of these biomarkers we employed an experimental model. Although the model does not mimic the actual physiological situation exactly, it does enable the identification of potential sources of specific analytes and to what extent incursion of blood components into the urine may influence the data. We previously used a similar model approach to demonstrate that BTA urine tests primarily detect a serum-based protein [6], and that NMP-22 urine tests monitor cellular turnover, rather a specific bladder tumor antigen [10].

Analyses from the model and the ELISA assays revealed different characteristics for CCL18 and A1AT with respect to them being potentially reliable $\mathrm{BCa}$ diagnostic biomarkers. For CCL18, the first observation is that three healthy control samples had very low urinary CCL18 levels $(5.96 \mathrm{pg} / \mathrm{ml})$. The median level of CCL18 in the non-cancer samples from the 308 subject cohort was also very low $(23.4 \mathrm{pg} / \mathrm{ml})$. A low baseline level is an advantage that can enable a clear distinction between healthy and disease state for a given assay. Conversely, if the differential between urine and blood is large, then a small amount of hematuria may have a significant impact. In the spiking experiment, we observed that $50 \mu \mathrm{l}$ of blood in $10 \mathrm{ml}$ of urine, a level that would be termed 'gross hematuria' in clinical tests, raised the CCL18 level in healthy controls to $31.9 \mathrm{pg} / \mathrm{ml}$, an increase of $\sim 5.3$ fold. In the 308 subject cohort, the median level of CCL18 was 10 -fold higher in BCa subjects $(230.5 \mathrm{pg} / \mathrm{ml}$ vs. $23.4 \mathrm{pg} / \mathrm{ml}$ ). The addition of benign and tumor cell lysates to the urine sample is designed to indicate whether the release of ubiquitous cellular factors may be the source of the biomarker. Increased cellular turnover is to be expected in a malignant condition, and so such factors, for example NMP22, may increase even though they are not actually cancer-specific biomarkers. Due to the low levels of CCL18 in the healthy urine samples, the addition of cell lysates from benign and tumor cells did significantly impact the CCL18 levels. Finally, immunohistochemical analysis of bladder tumor tissues revealed that CCL18 was present only in the inflammatory cells located in the stroma. No difference in the number of the immunoreactive cells was observed in benign versus cancerous tissue, or among the various grades or stages of bladder cancer. Together, these findings suggest that CCL18 monitoring is unlikely to be a reliable biomarker for the non-invasive detection of $\mathrm{BCa}$.

The analysis of the A1AT biomarker revealed opposite characteristics for the most part. ELISA data and the experimental model confirmed that A1AT is present at high levels in healthy and non-cancer subject urine samples. The median level in the 308 subject cohort was 120 $\mathrm{ng} / \mathrm{ml}$ in non-cancer cases, rising 5.5-fold to 606.4 $\mathrm{ng} / \mathrm{ml}$ in subjects with confirmed $\mathrm{BCa}$. The median level in the three healthy volunteer samples was intermediate $(1,170 \mathrm{ng} / \mathrm{ml})$. Lower levels in the non-cancer subjects from the ELISA data is most likely due to degradation with freezing and storage in these samples compared to the fresh urines obtained from the volunteers. The high baseline level of A1AT in healthy urine samples may not be ideal for diagnostic evaluation, but the impact of hematuria on A1AT assays would be expected to be less pronounced. Accordingly, gross hematuria in the 


\section{a}

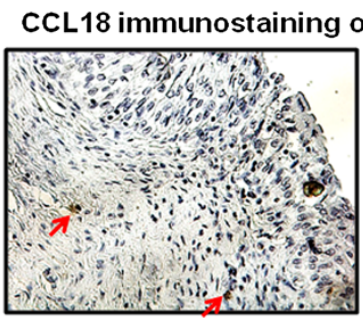

Normal urothelium

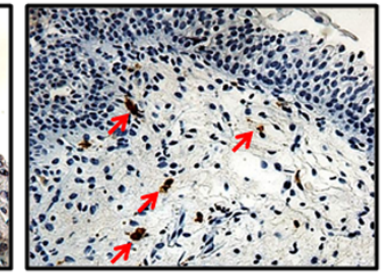

pTa/LG
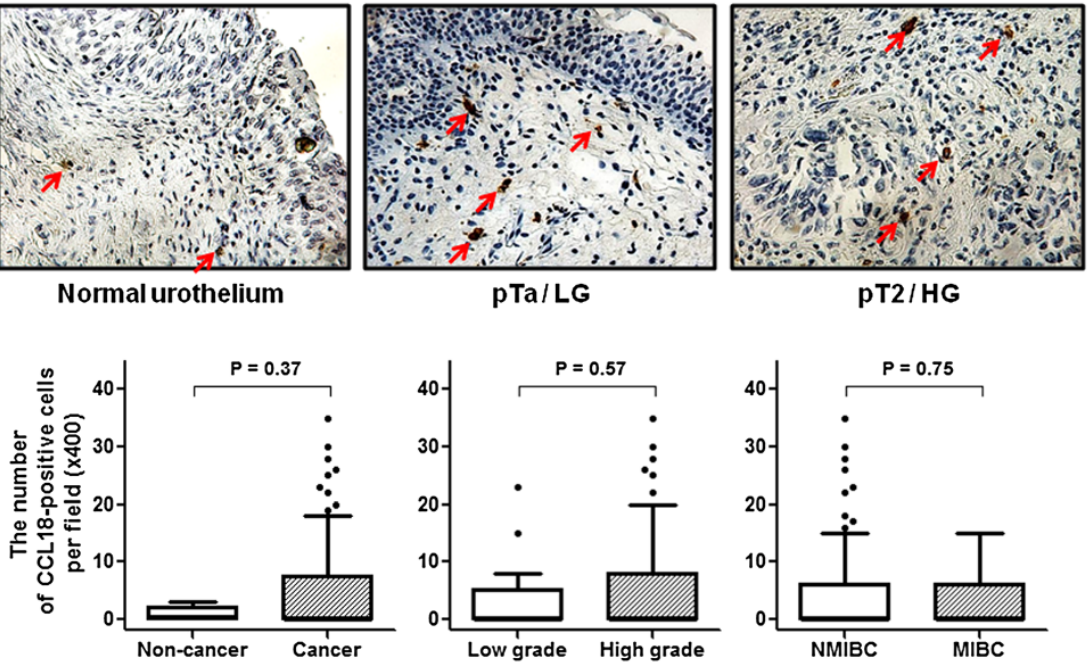

\section{b}

A1AT immunostaining of human bladder tissue

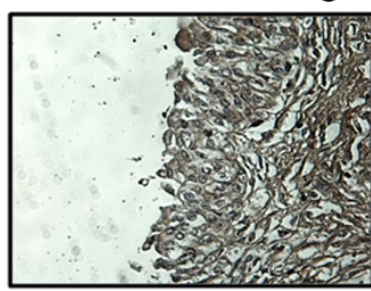

Normal urothelium

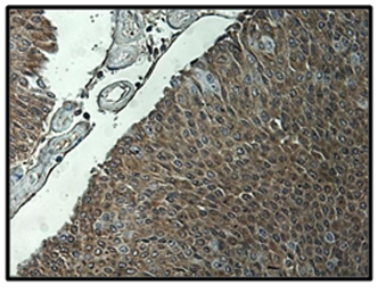

$\mathrm{pTa} /$ LG

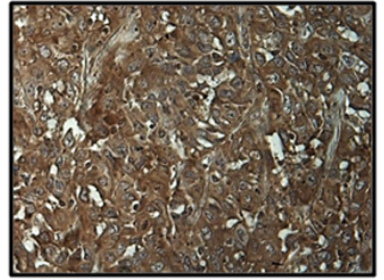

pT2/HG
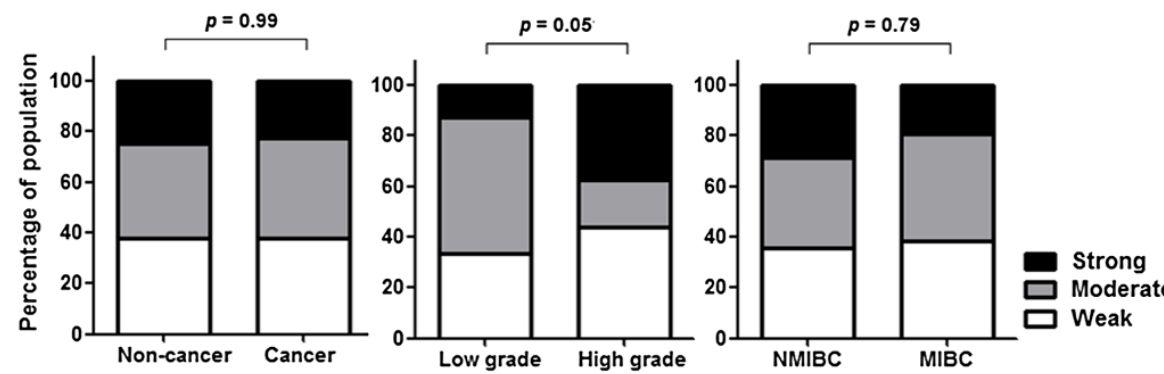

Figure 5 Assessment of CCL18 and A1AT in bladder tissue. a) Representative immunostaining of benign bladder for CCL18 (top-left), lowgrade non-muscle invasive bladder cancer for CCL18 (top-middle), and high-grade muscle invasive bladder cancer for CCL18 (top-right). Red arrows indicate CCL18-positive cells in the stroma. CCL18 staining was present only in inflammatory cells associated with the stroma. Lower panels are boxplots of CCL18 immunohistochemical staining intensity of benign bladder vs. bladder cancer, low-grade vs. high-grade, non-muscle invasive bladder cancer (NMIBC) vs. muscle invasive bladder cancer (MIBC). Error bars indicate standard deviations. Wilcoxon rank sum test was used to assess significance. b) Representative immunostaining of benign bladder for A1AT (top-left), low-grade non-muscle invasive BCa for A1AT (top-middle), and high-grade muscle invasive BCa for A1AT (top-right). A1AT staining was present in the cytoplasm and stroma. A1AT staining varied from weak and focal to strong and diffuse. Lower panel shows column bar graphs of A1AT immunohistochemical staining intensity of benign bladder vs. bladder cancer, low-grade vs. high-grade, NMIBC vs. MIBC.

experimental model (50 $\mathrm{\mu l}$ of blood into $10 \mathrm{ml}$ of urine) raised A1AT to $1,273 \mathrm{ng} / \mathrm{ml}$, an increase of only $9 \%$. Compare this to the $>400 \%$ rise in CCL18 in the same experimental model conditions. The addition of benign or cancer cell lysates in the experimental model had no impact on the A1AT levels. Previous preliminary research has linked the presence of urinary A1AT as a biomarker for renal dysfunction [32]. However we took precautions in our study to minimize renal dysfunction as a confounder by excluding subjects with a history of renal dysfunction as well as exclude subjects with grossly elevated urinary protein levels. Recently, researchers have reported that impaired renal function (i.e., reduced glomerular filtration rate) may adversely affect urinary 
biomarkers performance [33,34]. This is an excellent point and should be taken into consideration in future studies. However, we must stress that we confirmed these A1AT ELISA results by performing immunohistochemistry and thus demonstrated that A1AT is present within urothelial cells. We reported A1AT reactivity was epithelial in normal bladder tissue, and strongly positive in all tumor cells, specifically high-grade cells. Although A1AT IHC may not be particularly useful in differential histological evaluations, it does suggest that the source of the increased A1AT observed in BCa samples is most likely bladder tumor cells. The release into the urine may be via secretion or the turnover of tumor cells at the urine interface. Thus, even though normal urinary levels of A1AT are relatively high, measurement of this biomarker in the context of cancer detection may be worthwhile. The good separation between non-cancer and $\mathrm{BCa}$ urinary levels and the limited influence by secondary sources suggest that valid diagnostic cutoff thresholds may be possible for urinary A1AT monitoring.

When novel urinary biomarkers are proposed, the investigation of reliability in the face of potentially confounding effects is warranted, especially those introduced into the urine through bleeding, a common presenting factor in bladder tumor-bearing patients. Further studies into the utility of A1AT as a biomarker for the non-invasive detection of $\mathrm{BCa}$ are currently underway.

\section{Additional file}

\section{Additional file 1: Analysis of CCL18 and A1AT biomarker}

performance in an experimental model. Using the experimental

model depicted in Figure 1, urinary levels of CCL18 and A1AT were analyzed by ELISA. The addition of high concentration of benign cell lysate or medium to high concentration of cancer cell lysate resulted in an increase in CCL18. The addition of cells or cell lysate did not alter A1AT levels. Error bars indicate standard deviations. *, significance $(p<0.05)$ compared to pooled urines from healthy subjects. $\wedge$, significance $(p<0.05)$ compared to corresponding lower concentration.

\section{Competing interests}

Charles J. Rosser and Steve Goodison are officers for Nonagen Bioscience Corporation. Makito Miyake, Shanti Ross, Adrienne Lawton, Myron Chang, Yunfeng Dai, Lourdes Mengual, Antonio Alcaraz, Evan Gomes Giacoia have no COI.

\section{Authors' contributions}

MM: Acquisition of data. SR: Acquisition of data. AL: Acquisition of data. MC: Statistical analysis. YD: Statistical analysis. LM: Clinical samples, drafting of manuscript. AA: Clinical samples, drafting of manuscript. EGG: Acquisition of data. SG: Study concept and design, drafting of manuscript. CJ: concept and design, drafting of manuscript, funding. All authors read and approved the final manuscript.

\section{Acknowledgement}

This work was supported by research grants from Flight Attendant Medical Research Institute (CJR), Florida Department of Health James and Esther King Team Science Award 10KT-01 (CJR), Florida State James and Esther King
Biomedical Research Award Technology Transfer Feasibility 1 KF06 (SG) and National Cancer Institute RO1 CA116161 (SG)

\section{Author details}

'Cancer Research Institute, Orlando Health, Orlando, FL 32827, USA. 2Department of Pathology, Orlando Health, Orlando, FL 32806, USA ${ }^{3}$ Department of Biostatistics, University of Florida, Gainesville, FL 32601, USA. ${ }^{4}$ Laboratory and Department of Urology, Hospital Clínic, Universitat de Barcelona, Barcelona, Spain. ${ }^{5}$ Nonagen Bioscience Corporation, Orlando, FL 32827, USA. ${ }^{6}$ Section of Urologic Oncology, 1400 S. Orange Ave., Orlando, FL 32806, USA.

Received: 29 May 2013 Accepted: 3 September 2013

Published: 5 September 2013

\section{References}

1. Rife CC, Farrow GM, Utz DC: Urine cytology of transitional cell neoplasms. Urol Clin North Am 1979, 6:599-612.

2. Cajulis RS, Haines GK 3rd, Frias-Hidvegi D, McVary K, Bacus JW: Cytology, flow cytometry, image analysis, and interphase cytogenetics by fluorescence in situ hybridization in the diagnosis of transitional cell carcinoma in bladder washes: a comparative study. Diagn Cytopathol 1995, 13:214-23. discussion 24.

3. Heicappell R, Wettig IC, Schostak M, et al: Quantitative detection of human complement factor H-related protein in transitional cell carcinoma of the urinary bladder. Eur Urol 1999, 35(1):81-7.

4. Kinders $\mathrm{R}$, Jones $\mathrm{T}$, Root $\mathrm{R}$, et al: Complement factor $\mathrm{H}$ or a related protein is a marker for transitional cell cancer of the bladder. Clin Cancer Res 1998, 4(10):2511-20.

5. Oge O, Kozaci D, Gemalmaz H: The BTA stat test is nonspecific for hematuria: an experimental hematuria model. J Urol 2002, 167(3):1318-9. discussion 1319-20.

6. Miyake M, Goodison S, Rizwani W, Ross S, Bart Grossman H, Rosser CJ: Urinary BTA: indicator of bladder cancer or of hematuria. World J Urol 2012, 30(6):869-73.

7. Grossman HB, Messing E, Soloway M, Tomera K, Katz G, Berger Y, Shen Y: Detection of bladder cancer using a point-of-care proteomic assay. JAMA 2005, 293(7):810-6.

8. Sözen S, Biri H, Sinik Z, Küpeli B, Alkibay T, Bozkirli I: Comparison of the nuclear matrix protein 22 with voided urine cytology and BTA stat test in the diagnosis of transitional cell carcinoma of the bladder. Eur Urol 1999, 36(3):225-9.

9. Atsü N, Ekici S, Oge OO, Ergen A, Hasçelik G, Ozen H: False-positive results of the NMP22 test due to hematuria. J Urol 2002, 167(2 Pt 1):555-8.

10. Miyake M, Goodison S, Giacoia EG, Rizwani W, Ross S, Rosser CJ: Influencing factors on the NMP-22 urine assay: an experimental model. BMC Urol 2012, 12:23. doi:10.1186/1471-2490-12-23.

11. Rosser CJ, Liu L, Sun Y, Villicana P, McCullers M, et al: Bladder cancerassociated gene expression signatures identified by profiling of exfoliated urothelia. Cancer Epidemiol Biomarkers Prev 2009, 18:444-453.

12. Uriquidi V, Goodison S, Cai Y, Sun Y, Rosser CJ: Molecular Biomarker Signature for the Non-Invasive Detection of Bladder Cancer. CEBP; 2012.

13. Kreunin P, Zhao J, Rosser C, Urquidi V, Lubman DM, Goodison S: Bladder cancer associated glycoprotein signatures revealed by urinary proteomic profiling. J Proteome Res 2007, 6(7):2631-2639. Epub 2007 May 23.

14. Yang N, Feng S, Shedden K, Xie X, Liu Y, et al: Urinary glycoprotein biomarker discovery for bladder cancer detection using LC-MS/MS and label-free quantification. Clin Cancer Res 2011, 17:3349-3359.

15. Urquidi V, Kim J, Chang M, Dai Y, Rosser CJ, et al: CCL18 In a multiplex urinebased assay for the detection of bladder cancer. PLoS One 2012, 7:e37797.

16. Urquidi V, Goodison S, Kim J, Chang M, Dai Y, et al: VEGF, CA9 and angiogenin as a urinary biomarker for bladder cancer detection. Urology 2012, 79:1185-1188.

17. Urquidi V, Chang M, Dai Y, Kim J, Wolfson ED, et al: L-8 as a urinary biomarker for the detection of bladder cancer. BMC Urol 2012, 12:12-15.

18. Urquidi V, Goodison S, Ross Chang M, Dai Y, et al: Diagnostic potential of urinary alpha 1-antitrypsin and apolipoprotein $\mathrm{E}$ in the detection of bladder cancer. J Urol 2012, 188:2211-2214.

19. Goodison S, Chang M, Dai Y, Urquidi V, Rosser CJ: A multi-analyte assay for the non-invasive detection of bladder cancer. PLoS One 2012, 7(10):e47469. doi:10.1371/journal.pone.0047469. Epub 2012 Oct 19. 
20. Bossuyt PM, Reitsma JB, Bruns DE, Gatsonis CA, Glasziou PP, et al: Towards complete and accurate reporting of studies of diagnostic accuracy: the STARD initiative. Fam Pract 2004, 21:4-10.

21. Pisitkun $T$, Johnstone R, Knepper MA: Discovery of urinary biomarkers. Mol Cell Proteomics 2006, 5:1760-71.

22. Watanabe T, Shinohara N, Sazawa A, Harabayashi T, Ogiso Y, Koyanagi T, Takiguchi M, Hashimoto A, Kuzumaki N, Yamashita M, Tanaka M, Grossman $H B$, Benedict WF: An improved intravesical model using human bladder cancer cell lines to optimize gene and other therapies. Cancer Gene Ther 2000, 7(12):1575-80.

23. Rossi MR, Masters JR, Park S, Todd JH, Garrett SH, Sens MA, Somji S, Nath J, Sens DA: The immortalized UROtsa cell line as a potential cell culture model of human urothelium. Environ Health Perspect 2001, 109(8):801-8.

24. Fluss R, Faraggi D, Reiser B: Estimation of the Youden Index and its associated cutoff point. Biom J 2005, 47:458-472

25. Pepe MS, Feng Z, Janes H, Bossuyt PM, Potter JD: Pivotal evaluation of the accuracy of a biomarker used for classification or prediction: standards for study design. J Natl Cancer Inst 2008, 100:1432-8.

26. Chen J, Yao Y, Gong C, Yu F, Su S, Liu B, et al: CCL18 From tumorassociated macrophages promotes breast cancer metastasis via PITPNM3. Cancer Cell 2011, 19:541-55.

27. Zohny SF, Fayed ST: Clinical utility of circulating matrix metalloproteinase-7 (MMP-7), CC chemokine ligand 18 (CCL18) and CC chemokine ligand 11 (CCL11) as markers for diagnosis of epithelial ovarian cancer. Med Oncol 2010, 27:1246-53.

28. Wang Q, Li D, Zhang W, Tang B, Li QQ, Li L: Evaluation of proteomics-identified CCL18 and CXCL1 as circulating tumor markers for differential diagnosis between ovarian carcinomas and benign pelvic masses. Int: J Biol Markers; 2011.

29. Normandin K, Peant B, Le Page C, et al: Protease inhibitor SERPINA1 expression in epithelial ovarian cancer. Clin Exp Metastasis 2010, 27:55.

30. Lindor NM, Yang P, Evans I, et al: Alpha-1-antitrypsin deficiency and smoking as risk factors for mismatch repair deficient colorectal cancer: a study from the colon cancer family registry. Mol Genet Metab 2010, 99:157.

31. Hamrita B, Chahed K, Trimeche M, et al: Proteomics-based identification of alpha1-antitrypsin and haptoglobin precursors as novel serum markers in infiltrating ductal breast carcinomas. Clin Chim Acta 2009, 404:111.

32. Navarro-Muñoz M, Ibernon M, Bonet J, Pérez V, Pastor MC, Bayés B, CasadoVela J, Navarro M, Ara J, Espinal A, Fluvià L, Serra A, López D, Romero R: Uromodulin and $\mathrm{a}(1)$-antitrypsin urinary peptide analysis to differentiate glomerular kidney diseases. Kidney Blood Press Res 2012, 35(5):314-25.

33. Trojan B, Tang A, Chandrapal J, Filleur S, Nelius T: The clinical usefulness of nuclear matrix protein-22 in patients with end-stage renal disease and microscopic hematuria. Ren Fail 2013, 35(1):72-6.

34. Todenhöfer T, Hennenlotter J, Witstruk M, Gakis G, Aufderklamm S, Kuehs U, Stenzl A, Schwentner C: Influence of renal excretory function on the performance of urine based markers to detect bladder cancer. J Urol 2012, 187(1):68-73.

doi:10.1186/1471-2490-13-42

Cite this article as: Miyake et al:: Investigation of CCL18 and A1AT as potential urinary biomarkers for bladder cancer detection. BMC Urology 2013 13:42

\section{Submit your next manuscript to BioMed Central and take full advantage of:}

- Convenient online submission

- Thorough peer review

- No space constraints or color figure charges

- Immediate publication on acceptance

- Inclusion in PubMed, CAS, Scopus and Google Scholar

- Research which is freely available for redistribution

Submit your manuscript at www.biomedcentral.com/submit
( Biomed Central 